\title{
Políticas públicas para formação de professores de Ciências e Matemática: complementação pedagógica para bacharéis e tecnólogos
}

\section{Public policies for training science and mathematics teachers: pedagogic complementation for bachelors and technologists}

Klyvia Larissa de Andrade Silva Vieira ${ }^{1}$. Silmary Silva dos Santos ${ }^{2}$

\begin{abstract}
Resumo: Com este artigo, pretendemos participar das discussões acerca dos programas especiais de formação pedagógica para portadores de diploma de nível Superior. Em um primeiro momento, buscamos a compreensão desses cursos nos documentos oficiais, contextualizando-os como uma política pública para formação de professores. Em seguida, objetivando compreender como vêm sendo desenvolvidos estes programas no Brasil e suas implicações para a formação de professores de ciências e matemática, apresentamos uma análise de seis cursos de complementação pedagógica, localizados na internet e selecionados a partir dos critérios: (1) oferta de formação pedagógica para portadores de diploma de nível Superior para bacharéis e tecnólogos; (2) oferta da licenciatura plena em Ciências e/ou Matemática; e (3) apresentação, na página do programa, das disciplinas a serem cursadas.
\end{abstract}

Palavras-chave: Complementação pedagógica. Política pública. Formação de professores. Ensino de ciências. Ensino de matemática.

\begin{abstract}
The present article presents a theoretical discussion concerning the special programs of pedagogic formation for bearers of superior level diplomas (bachelors and technologists). In a first place, we looked for the understanding of those courses in official documents, such as LDB/96 and CNE/ $\mathrm{CEB}$ resolution $\mathrm{n}^{\circ} 02 / 97$, situating them a public policy to teacher training education. Afterwards we present the analysis of some complementary pedagogic courses available in Brazil, located on the internet and which we selected based on the criteria that: (1) They offer pedagogic formation for bearers of superior level diploma for bachelors and technologists; (2) They offer the full licensure in Sciences and/ or Mathematics; (3) They present, in program's webpage, the disciplines that will be studied. We aimed to understand how these programs have been developed in Brazil and their implications for Science and Mathematics teacher's education.
\end{abstract}

Keywords: Pedagogic complementation. Public policies. Teacher training education. Science education. Mathematics education.

\footnotetext{
${ }^{1}$ Departamento de Filosofia e Ciências Humanas, Universidade Estadual do Sudoeste da Bahia (UESB), Estrada do Bem Querer, Km 4, Caixa postal 95, CEP 45100-000, Vitória da Conquista, BA, Brasil. E-mail: larissa. edinho@gmail.com

${ }^{2}$ Programa de Pós-Graduação em Educação Científica e Formação de Professores de Ciências e Matemática, Universidade Estadual do Sudoeste da Bahia (UESB), Jequié, BA, Brasil.
} 


\section{Considerações iniciais}

A formação de professores constitui um alvo de discussões acirradas devido a sua importância, complexidade, e aos fatores sociais que explicam sua gênese, de forma que, segundo Chapani (2010, p. 20), "existe uma grande produção acadêmica sobre a questão da formação docente no Brasil, de tal maneira que esse campo de conhecimento já foi mesmo caracterizado como em 'estado de ebulição"'. Quanto ao profissional docente, como parte central desse processo - cuja função de mediar a apropriação do saber institucionalizado, da formação ética, moral e o desenvolvimento das "competências e habilidades" necessárias à demanda vigente da sociedade, tem o seu processo formativo engendrado o discurso acadêmico, como expõe Diniz-Pereira (1999, p. 2), ao evidenciar que

[...] a formação de professores tornou-se tema recorrente nas discussões acadêmicas dos últimos 30 anos. Com a criação das faculdades ou centros de educação nas universidades brasileiras, em 1968, a formação docente constitui-se em objeto permanente de estudos nesses espaços. É evidente, também, o crescimento da investigação sobre a profissão docente nas universidades e instituições de pesquisa no Brasil, principalmente a partir da década de 1990, o que tem possibilitado um debate fundamentado em análises empíricas e teóricas e, por conseguinte, uma discussão mais qualificada sobre o tema.

No discurso pós LDB 9.394/9633 (BRASIL, 1996), numa política neoliberal, a efervescência da formação de professores tornou-se mais acirrada do que outrora. O Brasil, com um "futuro promissor" de um país em desenvolvimento, abarcava a preocupação das organizações transnacionais ${ }^{4}$ em adequar a América Latina às novas contingências sociais de qualidade, eficiência, competitividade; e, em contrapartida, tornar acessível a educação de qualidade a todos, num caráter salvacionista (GURGEL, 2000). Assim por dizer, essas organizações têm suas origens em países centrais, desenvolvidos, e seguem em direção aos países periféricos, estabelecendo uma relação da educação com outros segmentos sociais, para, assim, exercer um efeito regulador (CHAPANI, 2010).

\footnotetext{
${ }^{3}$ Lei de Diretrizes e Bases da Educação Nacional, que foi promulgada em 1996, no governo do presidente Fernando Henrique Cardoso e do ministro da educação Paulo Renato Costa Souza. O texto dessa lei deixa em aberto questões referentes à formação de professores, que passarão a ser regulamentadas por dispositivos ordinários, sobretudo, por meio de resoluções e pareceres aprovados pelo Conselho Nacional de Educação (CNE) (LINHARES; SILVA, 2003).

${ }^{4}$ Podemos elencar como essas agências: a Organização das Nações Unidas para a Educação, Ciência e a Cultura (Unesco), o Fundo das Nações Unidas para a Infância (Unicef), o Banco Mundial (BM), que exercem influência política e econômica em outras nações. Dentre essas, destacamos o BM, que "vem dando ênfase especial à educação, entendida não apenas como instrumento de redução da pobreza, mas principalmente como fator essencial para a formação do capital humano adequado ao requisito do novo padrão de desenvolvimento. Esse banco tem ocupado, nos últimos anos, o papel de maior visibilidade no panorama educativo mundial, pois além do financiamento, transformou-se na principal agência de assistência técnica em educação e em fonte de referência de pesquisa importante no âmbito mundial. [...]” (CHAPANI, 2010, p. 43).
} 
A exemplo, podemos refletir sobre a influência do Banco Mundial, o "mandante financeiro" (BRZEZINSKI,1999), ao propor mudanças para melhorar a Educação Básica, com o menor custo possível, elaboradas por economistas e sem a participação direta dos professores. Esse órgão financeiro propõe modelos de formação docente, que expressam a preocupação em fornecer uma certificação, e o atendimento à necessidade global vigente.

A escola, por sua vez, como reflexo das "maiores mudanças na sociedade - política, econômica, social e culturalmente, a cada novo governo sofre um surto reformista [...]" (KRASILCHIK, 1987, p. 85) que orienta as ações no ambiente escolar, conduzindo-as ao atendimento das necessidades para o desenvolvimento de uma sociedade tecnológica, científica e globalizada, e da conscientização cidadã e política, expressando uma "verdadeira epidemia reformista a percorrer o globo, apresentando-se como única alternativa à tradição educacional e com uma disseminação dessa política globalizada" (CHAPANI, 2010, p. 41).

E, nesse sentido, impera a visão do profissional (da educação) que responda eficientemente a essas exigências, "levando a questionamentos sobre a função e a formação docentes" (CHAPANI, 2010, p. 52). A necessidade de "mão de obra especializada" torna-se, ainda, mais profícua ao considerar que uma ação docente que abarque essa dimensão traz, em si, uma complexidade que ultrapassa os limites de uma racionalidade técnica, como clarifica a autora supracitada, ao expor que, no que se refere à formação docente, a teorização tem demonstrado o seu caráter complexo, por apresentar muitas variáveis; e, nessa perspectiva, exige dos seus agentes uma grande destreza e um conhecimento interdisciplinar, ou seja, além do conhecimento específico da matéria a ser ensinada, o profissional da educação deve ter conhecimentos sobre a epistemologia, psicologia, sociologia etc. (CHAPANI, 2010). Conferindo, assim, a esse profissional, um domínio que ultrapasse a especificidade da disciplina que leciona.

Dessa forma, o processo formativo dos professores constitui peça central para o alcance das demandas sociais vigentes: qual a formação necessária para o sucesso do projeto de melhoria da qualidade do ensino, da educação?

O primeiro passo, então, é normatização para atuação docente, exigindo uma formação inicial mínima e obrigatória para o exercício profissional, como explicita o Título VI dos Profissionais da Educação, nos parágrafos 61 e 62 da LDB no 9.394/96:

Art. $61^{\circ}$. A formação de profissionais da educação, de modo a atender aos objetivos dos diferentes níveis e modalidades de ensino e às características de cada fase do desenvolvimento do educando, terá como fundamentos:

I - a associação entre teorias e práticas, inclusive mediante a capacitação em serviço;

II - aproveitamento da formação e experiências anteriores em instituições de ensino e outras atividades.

Art. $62^{\circ}$. A formação de docentes para atuar na educação básica farse-á em nível superior, em curso de licenciatura, de graduação plena, em universidades e institutos superiores de educação, admitida, como formação mínima para o exercício do magistério na educação infantil e nas quatro primeiras séries do ensino fundamental, a oferecida em nível médio, na modalidade Normal. (BRASIL, 1996, p. 24-25) 
Nesses artigos, aparece, de forma elucidativa, a formação de professores exigindo que os profissionais da Educação Básica tivessem formação Superior adquirida em universidades ou no Instituto Superior de Educação (IES), salvo para atuação nas séries iniciais do Ensino Fundamental, mediante diploma de curso Normal Médio (magistério) ${ }^{5}$.

A licenciatura passa a ter um caráter obrigatório. O Estado, por sua vez, precisa garantir e criar condições para a implementação e regulação dessa exigência. Políticas públicas educativas, como a atividade ou o conjunto de atividades que, de uma forma ou de outra, são imputadas ao Estado moderno capitalista ou dele emanam, providencialmente, são organizadas para contemplar a adequação dos estados e municípios à exigência em vigor, afastando-se, assim, da verdadeira função da implementação da política pública, como argumenta Chapani (2010, p. 41):

As políticas públicas deveriam originar-se, informar-se e recriar-se no solo de valores e normas orientados discursivamente. No entanto, tendo-se em vista as influências dos subsistemas Estado e mercado, por meio de suas ideologias de neutralidade, universalização e eficiência, de que modo as políticas públicas poderiam, de fato, ser recriadas? Penso que isso poderia ocorrer se fortalecesse as barreiras do mundo da vida capazes de conter o processo de colonização, só assim o poder estatal, responsável pelas políticas públicas, seria de fato informado por um mundo da vida racionalizado quanto aos fins aos quais tais políticas deveriam visar.

Para atender à exigência da licenciatura são criadas políticas públicas educativas para a formação de professores que não possuíam essa formação, tais como: Plano Nacional de Formação de Professores de Educação Básica (PARFOR), Pró-Infantil, Pró-Leigo, Normal Superior, entre outros. Esses cursos emergem a fim de licenciar os docentes que, com formação, apenas, em magistério, atuavam de forma desenfreada, sem formação específica, ou graduado em uma área, mas lecionando várias disciplinas.

Outro problema emerge de forma ainda mais gritante: professores graduados, sem licenciatura, ou seja, os bacharéis ou tecnólogos, que, apesar de possuírem o conhecimento técnico-específico, não tinham formação das disciplinas em educação. O problema, então, engendra a discussão e fomenta a elaboração de uma ação que viabilizasse a formação pedagógica e a atuação desses profissionais.

\section{Cursos de Complementação Pedagógica para Bacharéis ou Tecnólogos}

Mediante toda essa problemática, exposta anteriormente, após a promulgação da LDB 9.394/96, foi aprovada a Resolução CNE n 2/97, que ocasionou grandes embates a respeito

\footnotetext{
${ }^{5}$ No entanto, mudanças quanto à formação necessária para atuação e debates sobre a lei indicam, hoje, que a licenciatura em Pedagogia ou em Normal Superior para atuação na Educação Infantil e nas séries iniciais do Ensino Fundamental, seja uma exigência. (LIBÂNEO; PIMENTA, 1999).
} 
da complementação pedagógica para portadores de diplomas de curso Superior: bacharéis ou tecnólogos (BRASIL, 1997).

A finalidade dessa Resolução, que "dispõe sobre os programas especiais de formação pedagógica de docentes para as disciplinas do currículo do ensino fundamental, do ensino médio e da educação profissional em nível médio" (BRASIL, 1997, p. 1), segundo o seu Art. $1^{\circ}$, parágrafo único, é "suprir a falta de professores habilitados, em determinadas disciplinas e localidades, em caráter especial” (BRASIL, 1997, p. 1), exigindo que os ingressos nesses programas sejam portadores de diplomas de nível Superior, em cursos correlacionados à habilitação pretendida, e assim com uma "sólida base de conhecimentos na área de estudos ligada a essa habilitação” (BRASIL, 1997, p. 1) (Art. 2º).

Foi delegada às instituições de ensino, que se interessaram em oferecer esses programas, a responsabilidade de verificar a compatibilidade do candidato ao curso com a habilitação pretendida, ou seja, a sua formação inicial deve ter afinidade com a licenciatura que irá cursar, como explicita o parágrafo único, do Art. $2^{\circ}$ dessa Resolução.

Quanto à estrutura curricular, a organização acontecerá da seguinte forma: "Art. $3^{\circ}$ - Visando a assegurar um tratamento amplo e a incentivar a integração de conhecimentos e habilidades necessários à formação de professores, os programas especiais deverão respeitar uma estruturação curricular articulada" (BRASIL, 1997, p. 2).

Essa estrutura curricular organiza-se em três núcleos: (a) Núcleo contextual, que objetiva a compreensão do processo de ensino-aprendizagem no que se refere à prática de escola em todas as suas relações, seja no interior da instituição e/ou na comunidade em que está inserida; (b) Núcleo estrutural, diz respeito ao currículo, a organização sequencial dos conteúdos, avaliação e caráter interdisciplinar, e as metodologias que favoreceram o processo ensino-aprendizagem; (c) Núcleo integrador, preocupa-se com os problemas enfrentados pelos alunos, seja de ordem da aprendizagem ou, mesmo, do ensino, com vistas ao planejamento e reorganização do trabalho escolar, discutidos a partir de diferentes perspectivas teóricas, por meio de projetos.

A carga horária de quinhentas e quarenta horas, no mínimo, é assim definida no Art. $4^{\circ}$, das quais duzentas e quarenta horas são destinadas para os estudos teóricos, que podem ser realizados utilizando a metodologia semipresencial, na modalidade de ensino a distância (Art. $8^{\circ}$ ); e trezentas horas para a prática de atividades desenvolvidas em instituições de Ensino Básico, envolvendo todas as atividades próprias da vida escolar, incluindo: planejamento pedagógico, administrativo e financeiro, as reuniões pedagógicas, os eventos com participação da comunidade escolar, e a avaliação da aprendizagem, a fim de garantir a vivência nas relações e acontecimentos da realidade da escola (Art.10). Os estudantes concluintes desses programas receberão certificado e registro profissional equivalentes à licenciatura plena (BRASIL, 1997, 3-5).

Diniz-Pereira (1999) tece uma crítica que nos faz refletir sobre o formato desses cursos, ao expor sobre uma lógica de improvisação que transforma profissionais de outras áreas em professores, habilitando-os para o exercício da docência em cursos de complementação pedagógica, legitimados e regulamentados pela LDB, art. 63, inciso I, e pelo Parecer CNE no 04/97. Esses cursos apresentam uma carga horária de quinhentas e quarenta horas. Desse total, trezentas horas devem ser de prática de ensino (LDB, art. 65), e podem ser contabilizadas mediante capacitação em serviço (LDB, art. 61, inciso I). Para ele, essa formação constitui uma lógica de improvisação, ao permitir que profissionais egressos de outras áreas, mas exercendo o magistério, tenham uma formação docente de apenas duzentas e quarenta horas. Nesse sentido: 
O que parece inconcebível em outros campos profissionais - como, por exemplo, direito, medicina e engenharia - é possível para o magistério, contrariando a própria denominação do Título VI da LDB, "Dos profissionais da educação". Diante dessa situação preocupante, perguntar-se-ia: A mesma urgência que justificou, na década de 1970, no Brasil, a criação dos cursos de licenciatura de curta duração está presente nas atuais proposições sobre formação docente? São os programas de formação pedagógica para portadores de diplomas de educação superior uma reedição atualizada dos desastrosos cursos de licenciatura curta? Esse esquema é uma infeliz legitimação do "bico" na profissão docente, uma vez que profissionais egressos de outras áreas, que não optaram, de início, pela carreira de magistério, provavelmente, só estão na profissão enquanto não conseguem algo melhor para fazer.

(DINIZ-PEREIRA, 1999, p. 7)

\section{Analisando alguns cursos de complementação pedagógica existentes no Brasil}

As ideias apresentadas até aqui podem ser exemplificadas no discurso e na propaganda publicitária da Universidade Salgado Filho, campus de Salvador (BA), via internet ${ }^{6}$ :

A UNIVERSO oferece aos profissionais em exercício a chance de ampliar sua atuação profissional no magistério, através do Programa Especial de Formação de Docentes, que qualifica bacharelados de diferentes áreas do conhecimento. E proporciona a visão ampla da docência, através de uma complementação pedagógica. O programa possui uma sólida base pedagógica, habilitando o bacharel para o magistério nas disciplinas que integram as quatro séries finais do Ensino Fundamental, o Ensino Médio e a Educação Profissional em nível médio. O programa tem como propostas:

- Privilegiar a integração teoria-prática.

- Proporcionar uma visão ampla da docência, colocando o aluno em contato com os recursos didático-pedagógicos que auxiliam o professor no seu cotidiano.

- Além de oferecer o acesso ao magistério, habilitar professores que já estejam em exercício, oferecendo-lhes a complementação pedagógica com a capacitação em serviço, salvaguardando o plano curricular e a supervisão do curso.

- Carga horária: 570 horas (teoria e prática), em 12 meses.

- Aulas às sextas (tarde/noite) e sábados, em dias pré-determinados.

${ }^{6}$ Disponível em <http://www.universo.edu.br/portal/salvador/formacao-de-docentes/>. Acesso em: 23 maio 2013. 
O número de instituições de ensino que oferecem esse tipo de curso, de complementação pedagógica, no Brasil é bem amplo, fato que pode ser comprovado ao se realizar uma busca na internet, em sites de pesquisa, utilizando como dispositivo de busca o termo "Curso de Complementação Pedagógica", permitindo-nos observar a quantidade e a diversidade de programas que são encontrados.

Nesse sentido, com a finalidade de identificar e mapear estes cursos, realizamos consultas na internet no período de vinte e quatro de maio a cinco de junho do ano de 2013, fazendo uso das palavras-chave: "curso de complementação pedagógica" e "licenciatura para bacharéis e tecnólogos". Para melhor analisar os resultados, estabelecemos, inicialmente, três critérios: (1) Oferta de formação pedagógica para portadores de diploma de nível Superior para bacharéis e tecnólogos; (2) Oferta da licenciatura plena em Ciências e/ou Matemática; e (3) Apresentação, na página do programa, das disciplinas a serem cursadas.

A escolha por estes critérios foi motivada pela nossa preocupação em examinar, cuidadosamente, os resultados encontrados, a fim de atender aos objetivos deste estudo, bem como localizar os cursos que têm como foco a certificação em licenciatura em Ciências e/ou em Matemática para os bacharéis e tecnólogos, excluindo, assim, os cursos de complementação pedagógica com finalidade de capacitação e aperfeiçoamento de professores, bem como os que visam uma segunda licenciatura.

Aplicando o primeiro critério, encontramos 67 cursos, dos quais, com a aplicação dos demais critérios, eliminamos 61, pois não encontramos informações sobre a oferta das licenciaturas e das disciplinas a serem cursadas. Portanto, analisamos um total de seis cursos.

As instituições analisadas foram: Instituto de Educação do Espírito Santo (IESES); Faculdade Brasileira (FABRA); Centro Educacional de Apoio Pedagógico (CEAP/Goiânia); Universidade Vale do Rio Verde (UninCor); Educavix Consultoria Educacional; Instituto de Ciências Humanas João Paulo II (IJOPA).

A partir das informações referentes aos cursos de complementação pedagógica, retiradas das páginas das instituições, identificamos que todos os cursos analisados (conferir Quadro 1) destinam uma carga horária a atividades teóricas e, outra, a atividades práticas, que corresponde aos estágios supervisionados, conforme determina a Resolução CNE/CEB no 02/97, em seu art. $4^{\circ}$ (BRASIL, 1997), ao expor que os cursos devem ser desenvolvidos com duração mínima de quinhentas e quarenta horas, abrangendo uma parte teórica e prática, esta com duração mínima de, pelo menos, trezentas horas. Quanto ao período de duração dos cursos, observamos que eles devem ser desenvolvidos em até 12 meses, o equivalente a dois semestres, podendo ser concluídos em seis meses, ou seja, um semestre, para os alunos que realizarem as etapas da teoria e da prática no mesmo semestre.

Vale ressaltar que, nos componentes curriculares dos cursos, aparecem elementos que contemplam os temas: legislação educacional brasileira, psicologia da educação, didática, metodologias de ensino, e conteúdos específicos das áreas (matemática e ciência), e, em um dos cursos, na ementa, consta a disciplina Língua Brasileira de Sinais (LIBRAS).

Refletindo, assim, sobre a flexibilização quanto ao cumprimento da carga horária e a partir do olhar sobre as disciplinas a serem cursadas, questionamos: o período de seis a doze meses é suficiente para se trabalharem os conhecimentos minimamente necessários à formação docente? Como estes cursos e estas instituições vêm sendo avaliados e credenciados pelos órgãos competentes (Ministério da Educação e Conselho Nacional de Educação)? 
Quadro 1. Distribuição de carga horária dos cursos

\begin{tabular}{|l|c|c|c|}
\hline \multirow{2}{*}{\multicolumn{1}{|c|}{ Instituição }} & \multicolumn{3}{c|}{ Carga horária } \\
\cline { 2 - 4 } & Teórica & Prática & Total \\
\hline IESES & $280 \mathrm{~h}$ & $330 \mathrm{~h}$ & $610 \mathrm{~h}$ \\
\hline FABRA & $400 \mathrm{~h}$ & $300 \mathrm{~h}$ & $700 \mathrm{~h}$ \\
\hline CEAP/Goiânia & $700 \mathrm{~h}$ & $200 \mathrm{~h}$ & $900 \mathrm{~h}$ \\
\hline UninCor & Não consta & Não consta & Não consta \\
\hline Educavix Consultoria Educacional & $400 \mathrm{~h}$ & $300 \mathrm{~h}$ & $700 \mathrm{~h}$ \\
\hline IJOPA & $610 \mathrm{~h}$ & $300 \mathrm{~h}$ & $910 \mathrm{~h}$ \\
\hline
\end{tabular}

Fonte: websites das instituições citadas.

Levando em consideração as recomendações da Resolução CNE/CEB No 02/97 (BRASIL, 1997) no que diz respeito à modalidade de ensino dos programas especiais de formação pedagógica, todos os cursos analisados estão de acordo com esta resolução e oferecem o curso na modalidade semipresencial, sendo que, em todas as instituições analisadas, as atividades presenciais são desenvolvidas uma vez ao mês, preferencialmente nos dias de sábados.

Portanto, a partir dos dados obtidos, podemos concluir que: (a) Os modelos curriculares apresentados apontam para uma formação superficial e técnica dos professores, uma vez que, na maioria dos programas, a disciplina com maior carga horária corresponde à dos conteúdos específicos da área estudada; (b) A pesquisa não é contemplada nesses programas, visto que, em nenhuma das ementas localizadas, há indícios de atividades de pesquisa. Bem como não é solicitada atividade de conclusão de curso; (c) Os programas analisados possuem característica de políticas de formação com caráter emergencial, pois se propõem, em um curto espaço de tempo (um semestre ou dois semestres), habilitar profissionais para atuarem nas escolas para suprirem a falta de professores habilitados, especialmente nas disciplinas de Ciências e Matemática; (d) Há necessidade de melhor acompanhamento, orientação, planejamento e fiscalização dos cursos de complementação pedagógica, para que esses consigam promover melhores formações levando em consideração as exigências atuais para formação docente.

\section{Implicações da complementação pedagógica para a formação de professores de ciências e matemática}

A permissividade da lei quanto à organização dos cursos atrelada às necessidades do mercado impulsionou o aparecimento desses programas, como afirma Linhares e Silva (2008, 
p. 44): “[...] ao prever o aproveitamento de "outras atividades" expressão extremamente vaga e ampla, a Lei propiciou que experiências de formação vividas em áreas desvinculadas do campo educacional pudessem ser aproveitadas no processo de formação de professores".

Daí a importância dos programas especiais foi um passo relativamente simples, tendo em vista a carência comprovada de professores em algumas áreas, notadamente no ensino de das disciplinas da área de ciências da matemática e naturais e de línguas estrangeiras.

Quanto à formação de professores para a docência da Matemática e de Ciências, numa sociedade orientada, cada vez mais, pela ciência e tecnologia, a cobrança é ainda maior (CHAPANI, 2010), pois ultrapassa os limites da racionalidade técnica, da racionalidade prática e desenvolvendo atitudes para uma racionalidade crítica.

As necessidades formativas para esses profissionais preconizam uma série de exigências para o ensino dessas ciências, tais como: o pensamento e a ação na comunidade científica; a compreensão das influências ideológicas e socioeconômicas sobre a pesquisa científica; o desenvolvimento das competências comunicativas e do pensamento crítico que estimule o exercício da cidadania; a enculturação da cultura científica, bem como a apropriação dessa linguagem (CHAPANI, 2010). A autora ainda argumenta que:

A ampla literatura que a área de ensino de Ciências têm produzido no Brasil a respeito das necessidades formativas desses docentes leva-nos a questionamentos a respeito de como concretizar a formação de um profissional que possa dar conta da complexidade crescente dos conteúdos científicos, das questões relativas à natureza da ciência, das tensões sociais que se manifestam na escola, das novas demandas do mundo do trabalho, das exigências da cidadania, enfim, das possibilidades de conhecimento e de análise crítica dos pleitos da comunidade científica, do mundo do trabalho, dos anseios dos jovens, das demandas sociais, etc. Portanto, é imperativo uma formação inicial ampla e sólida que inclusive possibilite ao corpo docente a definição autônoma e responsável de suas necessidades relativas à formação em serviço. (CHAPANI, 2010, p. 218)

Dessa forma, urge questionar sobre a condição que os cursos de complementação pedagógica, com carga horária reduzida, têm para fomentar uma formação tão complexa. Se, para os cursos de licenciatura, de modalidade presencial e duração de quatro anos, os resultados apontam as falhas no processo de formação do professor, o que dizer da complementação pedagógica? Será que formação sólida, a ruptura da dicotomia teoria e prática, sugeridas pela Resolução CNE n ${ }^{\circ} 2 / 97$, efetivam uma formação para uma prática docente emancipadora? Ou apenas estamos diante de políticas públicas educativas que expressam a formação de professores correndo sérios riscos de improvisação, aligeiramento e desregularização. 


\section{Referências}

BRASIL. Lei $\mathbf{N}^{\circ}$ 9.394, de 20 de dezembro de 1996. Estabelece as diretrizes e bases da educação nacional. Disponível em: <http://www.planalto.gov.br/ccivil_03/leis/19394.htm>. Acesso em: 23 maio 2013.

BRASIL. Conselho Nacional de Educação. Resolução Nº 2, de 26 de fevereiro de 1997. Dispõe sobre os programas especiais de formação pedagógica de docentes para as disciplinas do currículo do ensino fundamental, do ensino médio e da educação profissional em nível médio. Disponível em: <http://portal.mec.gov.br/setec/arquivos/pdf_legislacao/rede/ legisla_rede_resol02.pdf $>$. Acesso em: 23 maio 2013.

BRZEZINSKI, I. Embates na definição das políticas de formação de professores para a atuação multidisciplinar nos anos iniciais do ensino fundamental: respeito à cidadania ou disputa pelo poder? Educação \& Sociedade, Campinas, v. 20, n. 68, p. 80-108, 1999.

CHAPANI, D. T. Políticas públicas e histórias de formação de professores de ciências: uma análise a partir da teoria social de Habermas. 2010. Tese (doutorado) - Faculdade de Ciências, Universidade Estadual Paulista, Bauru, 2010.

DIAS-DA-SILVA, M. H. G. F.; FERNANDES, M. J. S. As condições de trabalho dos professores e o trabalho coletivo: mais uma armadilha das reformas educacionais neoliberais? In: SEMINÁRIO DA REDESTRADO, 6., 2006, Rio de Janeiro. Anais... Disponível em: <http://www.fae.ufmg.br/estrado/cd_viseminario/trabalhos/eixo_tematico_1/as_ condicoes_de_trab_do_prof.pdf $>$. Acesso em: 23 maio 2013.

DINIZ-PEREIRA, J. E. As licenciaturas e as novas políticas educacionais para a formação docente. Educação \& Sociedade, Campinas, v. 20, 68, p. 109-125, 1999.

GURGEL, C. M. A. Políticas públicas e educação para a ciência no Brasil (1983-1997): afinal o que é ensino de qualidade? Revista Iberoamericana de Educación, Madrid, 22 fev. 2000.

KRASILCHIK, M. O professor e o currículo das ciências. São Paulo: EPU: Edusp, 1987. (Temas básicos de educação e ensino).

LIBÂNEO, J. C.; PIMENTA, S. G. Formação de profissionais da educação: visão crítica e perspectiva de mudança. Educação \& Sociedade, Campinas, v. 20, n. 68, p. 239-277, 1999.

LINHARES, C.; SILVA, W. C. Formação de professores: travessia crítica de um labirinto legal. Brasília: Plano Editora, 2003.

Artigo recebido em 28/08/13. Aceito em 02/03/15. 